Discussion Paper No. 02-54

Optimal Cover Prices and the Effects of Website Provision on Advertising and Magazine Demand

Ulrich Kaiser

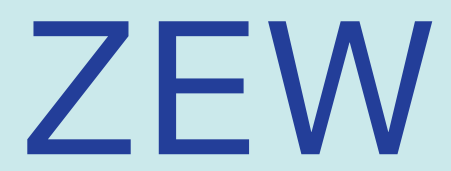

Zentrum für Europäische Wirtschaftsforschung GmbH

Centre for European

Economic Research 
Discussion Paper No. 02-54

\title{
Optimal Cover Prices and the Effects of Website Provision on Advertising and Magazine Demand
}

\author{
Ulrich Kaiser
}

Download this ZEW Discussion Paper from our ftp server:

\begin{abstract}
ftp://ftp.zew.de/pub/zew-docs/dp/dp0254.pdf
\end{abstract}
Die Discussion Papers dienen einer möglichst schnellen Verbreitung von neueren Forschungsarbeiten des ZEW. Die Beiträge liegen in alleiniger Verantwortung der Autoren und stellen nicht notwendigerweise die Meinung des ZEW dar.

Discussion Papers are intended to make results of ZEW research promptly available to other economists in order to encourage discussion and suggestions for revisions. The authors are solely responsible for the contents which do not necessarily represent the opinion of the ZEW. 


\section{Non-technical summary}

Print media markets have two unique features. First, market actors are faced by two interrelated demand curves: the demand for advertising and the demand for the print medium itself. Consequently, the print media industry's pricing behavior is different from the pricing behavior of traditional industries where there is just one demand curve. Second, print media have recently started to produce an at least potentially perfect substitute for their initial product, namely newspaper and magazine websites.

This paper studies the price-setting behavior of German women's magazines and also provides empirical evidence on the extent to which website provision affects the demand for magazines and the demand for advertising space.

It is shown that magazines whose advertising demand is highly cover-price elastic (e.g. inverse advertising demand strongly reacts to changes in cover prices) price their products markedly below marginal cost. Another important result of this paper is that website provision neither significantly affects magazine demand nor advertising demand. 


\title{
Optimal cover prices and the effects of website provision on advertising and magazine demand
}

\author{
ULRICH KAISER* \\ University of Southern Denmark at Odense \\ Centre for European Economic Research
}

August 1, 2002

\begin{abstract}
I derive and estimate a model for cover price setting in print media markets where actors are faced by two interrelated demand curves: the demand for the print medium and the demand for advertising space. Publicly available data on German women's magazines observed between 1998 and 2001 are used in the GMM estimation. Main findings are that my estimated marginals cost coincide well with those of industry sources, magazines with a high circulation elasticity of advertising demand price markedly below marginal cost and website provision neither has a significant effect on magazine nor on advertising demand. Keywords: magazines, cost estimation, GMM estimation, website provision JEL classification: L11, C33
\end{abstract}

\footnotetext{
*Address: Ulrich Kaiser, University of Southern Denmark, Dept. of Economics, Campusvej 55, DK-5230 Odense M, Denmark; phone: +45 6650 3363, fax: +45 6615 8790, email: uka@sam.sdu.dk; http://www.sam.sdu.dk/staff/uka and Centre for European Economic Research, Mannheim, Germany.

Acknowledgements: I wish to thank Christine Konrad and Laura Berndt of Gruner + Jahr, Carmen Basler of Burda Advertsing Center, Linda Knab of Arbeitsgemeinschaft Media-Analyse and Birgit Zöllner of Jahreszeitenverlag for kind data provision and advice. Ulrike Haßlöcher of Michael Conrad \& Leo Burnett helped me to look at the advertising market from an advertisers perspective and Jörg Hüner of Megalith-Software provided me with expert knowledge on printing technology and printing cost components. I also gratefully acknowledge helpful comments received from seminar participants at Harvard University and the NBER, in particular John Asker, Ernst R. Berndt, Richard E. Caves, Iain Cockburn, Liran Einav, Matt Gentzkow, Julie M. Mortimer, Ariel Pakes and Minjae Song. Significant useful contribution also came from the participants of the conference on "The Economics of Information and Communication Technologies" at the Centre for European Economic Research, especially from my discussant Joachim Winter, Julia Häring and Michael Ward. This research was undertaken while I was visiting Harvard University and the NBER in the academic year 2001/2002. I am indebted to the VolkswagenStiftung for funding my reserach visit within the 'Empirical Economics - Program of Fellowships for German Researchers in the United States' program and to the NBER, especially to Ernst R. Berndt, for hosting me during the academic year 2001/2002.
} 


\section{Introduction}

Print media markets have two unique features. First, newspapers and magazines are faced by two different demand curves: the demand for copies of the print medium and the demand for advertising space. Such a 'demand interdependence' (Rosse, 1978) has important consequences on print media pricing since an increase in cover prices leads to a decrease in magazine demand which in turn induces a reduction in the demand for advertising space. Second, by launching websites, newspapers and magazines nowadays increasingly often start to produce an at least potentially perfect substitute for their initial product.

This paper analyzes both special features of print media markets. It (i) derives and estimates a model for optimal cover prices using publicly available quarterly data on the German women's magazine market between 1998 and 2001 and (ii) analyzes the effects of website provision on circulation and advertising demand. It is well documented that print media often charge cover prices that are below marginal cost in order to keep circulation high, thereby maintaining a high demand for advertising space (Blair and Romano 1993; Wagner 1981). Earlier studies (Blair and Romano 1993; Bucklin et al. 1989; Chaudhri 1998; Corden 1952-1953; Dertouzos and Trautman 1990; Ferguson 1983; Merrilees 1983; Rosse 1967,1970; Thompson 1989), however, assume that print media firms can determine both cover prices and advertising price (or the number of copies and advertising space if the equilibrium is assumed to be Nash in quantities). That print media firms actually have command over the advertising market seems to be unreasonable since the main factor influencing advertising demand is the number of readers 'produced' by the print medium. This implies that print media firms, by setting appropriate cover prices, have only indirect command over the demand for advertising. More recent studies such as those by Berry and Waldfogel (1999), who analyze radio broadcasting, and Rysman (2000), who studies Yellow Pages, indeed define inverse-demand functions for advertising that depend upon the number of persons reached (or 'produced') by the medium. I follow their approach and derive a first-order condition for optimal cover prices that takes into account the feedback of cover prices to advertising demand. In addition to this first-order condition, the joint estimation problem consists of an equation for the inverse demand for advertising (which is derived from a constant elasticity framework) and an equation for magazine demand (for which I choose a nested logit demand specification). These three equations are jointly estimated by GMM.

A somewhat natural test for the validity of my model is to compare the estimated marginal cost derived from the first-order condition with information on 'actual' marginal cost from information gathered from the printing and publishing indus- 
try. ${ }^{1}$ Such a comparison suggests that my model produces results that generally coincide very well with industry data.

The possibility to estimate marginal cost of production without using cost data relates this paper to early work by Rosse $(1967,1970)$, who also derives marginal cost estimates from first-order conditions and who illustrates his approach by estimation results for the US newspaper industry. The interest in estimating marginal cost without using cost data has recently revived in the context of merger analysis where merging firms often claim that returns to scale was major reason to merge. If such cost efficiencies exist and they overweigh price increases due to gains in market power, then the merger might actually decrease prices and competition authorities might be less reluctant to approve the proposed concentration (Berry and Pakes 1993; Röller et al. 2000).

The attention of this paper is restricted to women's magazines because this is the segment of the German magazine market where competition is fiercest. ${ }^{2}$ The general benefit form restricting attention to a single subsegment of the magazine market is that estimation results can be displayed and discussed for individual magazines, an issue that is especially valuable with respect to the internal and external validation of the estimation results.

In December 2001, twelve out of the total of 36 German women's magazines analyzed in this paper provided a website. Magazines that provide a website have a readership that is significantly more internet-affluent than that of magazines that are still offline. This, in addition to the fact that there are very limited substitution possibilities between the online and the print version of the magazines suggests that website provision is to be regarded as a quality characteristic of the magazine from the consumers' perspective. Likewise, the fact that all magazine websites directly or indirectly (via links) provide information that is valuable for advertisers indicates that website provision is a quality characteristic from the advertising clients' perspective as well. Hence, website provision is treated as a quality characteristic both in the magazine demand and the advertising demand equation.

The estimation results indicate that website provision neither has a significant effect on magazine demand nor on advertising demand. Website provision hence neither is a threat to magazine demand nor is it a means for attracting advertisers and magazine purchasers. The latter result coincides with Gentzkow (2002), who uses data on purchasers of the L.A. Times to demonstrate that website visiting

\footnotetext{
1'Actual' is put into quotation marks since the industry sources also base their marginal cost assessments on approximations.

${ }^{2}$ In 2001, 36 women's magazines titles are published, more than twice as much as in the second-densely populated segment, TV magazines. Market concentration, as measured by the Hirshman-Herfindahl index, is much lower in women's magazines than in any other segment, and this is true both in the magazine demand and in the advertising demand dimension. Women's magazines also possess the largest overall market shares in terms of circulation and advertising demand. These figures are based on data contained in Gruner + Jahr (2002).
} 
only has a small impact on the demand for the L.A. Times' print version. Kaiser (2002) also does not find significant effects of website provision on magazine demand using annual data on magazines that are far less detailed than the data used here. ${ }^{3}$

Further results of this paper are that (i) magazines with a high sensitivity of advertising prices with respect to cover prices charge copy prices that are markedly below marginal costs, (ii) there is a concave effect of both the number of editorial pages and the share of advertising pages per issue, with magazine demand maxima being reached at 155 editorial pages and an advertising share of 40.6 per cent respectively, (iii) consumers appreciate topic variety and (iv) advertisers value topic concentration.

The outline of this paper is as follows: Section 2 descriptively analyzes website contents of the women's magazines considered here, Section 3 sets up the theoretical framework for the structural empirical analysis, Section 4 describes the data and the specification of the empirical model, Section 5 describes estimation results and compares the estimated marginal cost with data obtained from industry sources and Section 6 concludes.

\section{The website provision issue}

Launching a website is a costly venture. There are considerable setup costs and, even more importantly with regard to high labor costs in Germany and its tight market for IT experts, high costs of maintaining a website. The fact that magazines do launch websites, and do so with increasing pace, indicates that there must be incentives of going online that compensate for setup and maintenance costs. As shown in Table 1, twelve (out of a total of 36 women's magazines), provide a website in the fourth quarter of 2001. The table also provides the website address and indicates the corresponding magazine group. Five magazine groups are differentiated according to industry sources (Jahreszeitenverlag 1999-2002), and only one group, 'weekly entertaining women's magazines', does not provide websites. These magazines target women older than 70 years so that it is quite unsurprising that none of these magazines run a website.

Insert Table 1 about here!

In the following I will advocate four main reasons for website launching. First, magazines want to provide complementary and additional information to the one contained in the current print version (which implies that substitution away from the print version towards the online version is very limited). Second, magazines

\footnotetext{
${ }^{3}$ Kaiser (2002) also restricts attention on magazine demand and neither analyzes cover pricing nor advertising demand.
} 
want to provide easily accessible information on readership, advertising prices and magazine contents to potential advertisers. Third, magazines use their internet appearance as a device to advertise the current print edition and to provide online subscription possibilities. Fourth, a magazine that already is online might just have disliked to eventually become the last to launch a website.

I base these statements on the following observations: first, in contrast to newspapers and news magazines which basically put up the entire set of articles contained in the print edition on the internet, women's magazines' websites do not provide access to articles or reports contained in the current print version. Instead, they provide access to articles that appeared in past issues and information that is additional to the one contained in the print issue, and many magazines crossreference their websites for further information in their print version articles. Popular headings of the webistes are basically the same as those of the printed magazines and include 'Job \& Career', 'Love \& Partnership', 'Beauty \& Fashion' and 'Vacation', where links lead to related articles that appeared in past issues of the magazine. Interestingly, all websites provide a daily updated horoscope, a service that is truly complementary to the information provided in the print version. A further indication of complementarity is that one of the magazines studied here, 'Brigitte', claims that 95 per cent of the website visitors also purchase the print copy. ${ }^{4}$

The issue of website provision as a quality characteristic is further advanced by Table 2 which displays differences in internet use by readers of magazines that are online and of magazines that are offline. More than a quarter of readers of women's magazines that provide a website have access to the internet, and 22 per cent regularly use it at home. By contrast, only eleven per cent of the readers of magazines that are still offline have internet access, and 9.4 per cent regularly use it in private. The table clearly indicates that readers of magazines with website provision are significantly more internet-affluent that readers of magazines that do not run a website. This points readership-induced website launching.

Second, all magazine websites either directly or indirectly (via links) provide advertiser-specific information. One magazine, 'Madame', even runs a website for advertisers only. ${ }^{5}$ Further, by providing a website, advertisers are enabled to take a quick look on the design and contents of the magazine.

Third, the table of contents and/or a picture of the title page of the current print edition are used as eye-catchers by almost all of the magazine websites. Moreover, all websites also provide the possibility to subscribe online. ${ }^{6}$ These

\footnotetext{
${ }^{4}$ This statement is made on the publisher's website at http://www.ems.guj.de/portfolio/index_fremd.html?http://www.ems.guj.de/portfolio/port.php?id=2\&header=brigitte. $\quad$ I was unable to obtain related information for the other magazines.

${ }^{5}$ Therefore, 'Madame' is treated as having a website in the estimation of the equation for the inverse demand for advertising and as not having a website in the magazine demand equation later on.

${ }^{6}$ One exception is 'Bild der Frau' which cannot be subscribed at all.
} 
facts highlight the importance of self-advertising as a reason to launch a website. Bernd Ziesemer, editor-in-chief of the daily 'Handelsblatt', the German equivalent to the 'Financial Times', said in a round table discussion hosted by the German Federal Ministry of Education and Research in Berlin on November 9, 2001: "Most websites are run at a loss. In certain areas, for example in online subscription, website provision actually pays off."

Fourth, Table 1 suggests that there are distinct patterns of website entry. The first magazine that launched a website was 'Allegra' in January 1996. One year after, 'Amica', a close competitor of 'Allegra', also went online. Another year later, 'Cosmopolitan' launched a website. These magazines belong to the same magazine group, which is termed 'Monthly medium-priced women's magazines' by the industry (Jahreszeitenverlag 1999-2002). Similar patterns are present for the other magazine groups as well, suggesting that once one competitor launched a website, this induces the other magazines to follow so that not wanting to be the last to go online in fact appears to be a valid argument for website launching.

Insert Table 2 about here!

The most important takeaway so far is that website provision is to be regarded as a quality characteristic of a magazine, both from the magazine purchaser's and the advertiser's perspective — and I will treat website provision accordingly in the estimations for magazine demand and advertising demand.

There are obviously a number of additional reasons to launch a website. These do neither affect the derivation of the model for optimal cover pricing nor do they have an impact on the estimation results. For completeness, they might, however, worth being mentioned.

It seems reasonable to believe that at least the early website launchers, those which launched websites between 1996 and 1998, hoped to gain additional revenues from e-commerce and online advertising (and potentially from cross-selling in advertising). Given the fact that many ambitious e-commerce projects that were linked to the women's magazines websites such as www.go-on.de and later www.kaufrausch.de (the e-commerce partners of 'Allegra') went offline in July 2001 and March 2002 respectively indicates that, unless they acted completely irrationally, the late website launchers did not put high hopes into e-commerce. Aside from the 'Allegra' failures, other flops include www.sheego.com, a joint internet portal of one of Germany's leading publishing houses and Germany's leading mail-order business, which went offline in December 2001 after only six months of operation, and www.dock23.com, which was run by another large German publishing house.

By the same token, online advertising via banner or popup-ads still plays a very minor role in Germany. In a recent study, ACNielsen (2002) finds that 700 websites cover 70-80 per cent of the entire internet advertising market (and these 
70-80 per cent do not include any of the websites considered in this study). Visits to the women's magazine websites in October 2001, February 2002 and April 2002 show that these websites very rarely display banner ads and popup-ads. The low success of e-commerce and online-advertising also shows up in a study by the German Publisher Association (Deutsche Fachpresse, 2001) who finds that $74 \%$ of all websites do not cover running costs.

\section{The model}

There is an abundant literature on print media industries that started with the diagrammatic exposition of the newspaper firms' profit maximization problem by Corden (1952-1953), who was the first to formally analyze the interrelationship between advertising sales and magazine sales. Later studies, to a large extent motivated by the occurrence of 'one-newspaper cities' in Australia (Merrilees 1983, Chaudhri 1998) and the US (Blair and Romano 1993; Bucklin et al. 1989; Dertouzos and Trautman 1990) and by a generally increasing degree of industry concentration (Ferguson 1983; Reddaway 1963; Thompson 1989), were concerned with the effects of concentration on the newspaper market. By and large, these studies find that competitive concerns are weakened by the fact that the newspaper firms' pricing behavior is restricted by the feedback of newspaper pricing to the advertising market.

The model introduced below explicitly takes the interrelationship between magazine sales and advertising demand into account. Unlike the aforementioned studies which assume that print media firms have command both over the magazine market and the advertising market, I treat advertising demand as being mainly determined by the demand for magazines. This implies that magazines only have indirect discretion over advertising demand: their cover price setting takes the feedback from magazine sales to advertising demand into account.

By making advertising demand a function of readership, I follow more recent approaches to model advertising demand by Berry and Waldfogel (1999) as well as Rysman (2000). Specifically, I adopt the constant elasticity function for the inverse demand for advertising used by Berry and Waldfogel (1999):

$$
p_{j t}^{a}=\lambda_{j t}\left(M_{t} s[\boldsymbol{p}, \boldsymbol{x}, \boldsymbol{\xi}, \boldsymbol{\theta}]\right)^{\eta},
$$

where $p_{j t}^{a}$ denotes the price per advertising page of magazine $j$ at time $t,{ }^{7} M$ denotes market size - which I define, in accordance to industry practice (AG.MA

\footnotetext{
${ }^{7}$ There actually exist three different advertising prices that differentiate between black and white, two-color and four-color advertising pages. I use the weighted (by the respective number of advertising pages) average of advertising prices. All prices are in German Marks (DM). The Euro/DM exchange rate is 1.9853 .
} 
2001) as the number of women aged 14 years and above - $s[$.$] denotes the mar-$ ket share of magazine $j$ at time $t$ which depends on the cover prices of magazine $j$, $p_{j}^{c}$, and of all other magazines ${ }^{8}$ observed quality characteristics of magazine $j$ and all other magazines, $\boldsymbol{x}$, and unobserved quality characteristics of magazine $j$ and all other magazines, $\boldsymbol{\xi}$. Market shares depend on the observed and unobserved quality characteristics of magazine $j$ and all other women's magazines. The vector $\boldsymbol{\theta}$ consists of the parameters relating the observed quality characteristics to magazine demand, $\boldsymbol{\beta}$, of the parameter corresponding to magazine price, $\alpha$, and of the correlation coefficient of within-group utility correlation, $\sigma$ (which is discussed below). The product $M_{t} \cdot s[$.$] hence gives the circulation of magazine j$ at time $t$. The parameter $\lambda$ depends upon observed and unobserved variables that shift the demand for advertising. The parameter $\eta$ is what Corden (1952-1953, p. 182) termed 'circulation elasticity of the demand for advertising': the larger $\eta$, the more elastic are advertising prices with respect to circulation. There hence exists a direct mapping between circulation and advertising price.

While Berry and Waldfogel (1999), although they also decompose market participants in different groups in their demand estimation, only specify a single circulation elasticity of demand, $\eta$, I allow for more flexibility by letting the circulation elasticities be different for different magazine groups since it appears obvious that advertising in fashion magazines such as 'Elle' and 'Vogue' is less circulation elastic than in weekly entertaining magazines with a broad topic variety. My inverse demand for advertising specification hence is:

$$
p_{j t}^{a}=\lambda_{j t} \prod_{g}\left(M_{t} s[\boldsymbol{p}, \boldsymbol{x}, \boldsymbol{\xi}, \boldsymbol{\theta}]\right)^{D_{g} \eta_{g}}=\lambda_{j t}\left(M_{t} s[.]\right)^{\sum_{g} D_{g} \eta_{g}},
$$

where $D_{g}$ denotes a dummy variable that is coded one if magazine $j$ is in subgroup $g$ and zero otherwise.

The demand-shift parameter $\lambda$ is assumed to depend upon a vector of observed variables that influence advertising prices, for example readership characteristics and website provision, summarized by vector $\boldsymbol{w}_{j \boldsymbol{t}}$, and an unobserved (to the econometrician) component that is denoted by $\psi_{j t}$ :

$$
\lambda_{j t}=\exp \left(\boldsymbol{w}_{\boldsymbol{j} \boldsymbol{t}} \boldsymbol{\kappa}+\psi_{j t}\right) .
$$

Magazine $j$ 's profit function is given by:

$$
\Pi_{j t}=\left(p_{j t}^{c}-m c_{j t}\right) M_{t} s[\cdot]+p_{j t}^{a} A D P_{j t}-F_{j t},
$$

where $m c_{j t}$ denotes marginal cost of producing one copy of magazine $j$ at time $t$, $A D P$ denotes the number of advertising pages and $F$ denotes fixed production

\footnotetext{
${ }^{8}$ Note that consumers cannot save from magazine subscription since subscription and cover prices are, with three exceptions, identical in the German magazine market. This issue is discussed in greater detail by Kaiser (2002).
} 
cost.

Magazines are assumed to be price-setters, an assumption that seems to be justified with regard to (i) the feedback of cover prices to advertising demand and (ii) the fact that advertising demand is not influenced by the total number of printed copies but by the total number of magazines effectively sold (so just increasing the number of printed copies does not increase advertising demand). Ignoring second-order effects of cover prices on consumer utility via the number of advertising pages, e.g. assuming that $\partial s[.] / \partial A D P_{j t} \cdot \partial A D P_{j t} / \partial p_{j t}^{c}=0$, leads to the following first-order condition:

$$
\frac{\partial \Pi_{j t}}{\partial p_{j t}^{c}}=M_{t} s[.]+M_{t}\left(p_{j t}^{c}-m c_{j t}\right) \frac{\partial s[.]}{\partial p_{j t}^{c}}+\frac{\partial p_{j t}^{a}}{\partial p_{j t}^{c}} A D P_{j t}=0
$$

Rearranging terms and using the specification for inverse advertising demand as in Equation (2) leads to the following decomposition of magazines' markup:

$$
p_{j t}^{c}-m c_{j t}=\underbrace{-\sum_{g} \eta_{g} D_{g} \frac{p_{j t}^{a} A D P_{j t}}{M_{t} s[.]}}_{\begin{array}{c}
(-) \\
\text { markup } \\
\text { deterioration }
\end{array}} \underbrace{-\frac{s[.]}{\partial s[.] / \partial p_{j t}^{c}}}_{\begin{array}{c}
(+) \\
\text { 'usual' } \\
\text { markup }
\end{array}} .
$$

Cover prices hence deviate from the usual price-equals-marginal-cost-plus-amarkup formula of oligopoly models by a 'markup deterioration' that depends upon the circulation elasticity of advertising demand and advertising revenue per copy: the less circulation-elastic advertising demand (given advertising revenue per copy) and the higher given advertising revenue (given the circulation elasticity of advertising demand), the higher is the cover price (and vice versa). Magazines hence cannibalize cover prices in order to increase advertising sales. Marginal cost might even exceed cover prices if advertising demand is very circulation elastic and/or if magazines make large revenues from advertising sales. Below marginal cost pricing is a well documented phenomenon in the newspaper industry (Blair and Romano 1993; Wagner 1981) and it also turns to be present for some segments of the German women's magazines market.

A somewhat 'natural' test of the validity of my model is to compare the marginal cost estimates obtained from Equation (6) to marginal cost data obtained from industry sources, an exercise that shall be conducted below.

Magazine demand is specified by a 'nested logit' functional form (Berry 1992). The baseline idea here is to place products into different groups such that products within a group are similar to one another and products of different groups are dissimilar. The correlation between magazines within the same group is represented by parameter $\sigma$, a parameter that is to be estimated. By differentiating between products of different subgroups, a gain in flexibility compared to the 
standard logit-type model of differentiated products demand (Anderson et al. 1992) is obtained since own-price and cross-price elasticities no longer only depend upon own market shares but also upon within-group market shares and the correlation coefficient $\sigma$. The nested logit model nests the simple logit approach in the correlation coefficient $\sigma$ : if $\sigma=1$, products are perfect substitutes within groups and if $\sigma=0$, products are symmetric and the standard logit model is obtained.

The nested logit demand model is given by:

$$
\ln \left(s_{j t}\right)-\ln \left(s_{0 t}\right)=\boldsymbol{x}_{\boldsymbol{j} \boldsymbol{t}} \boldsymbol{\beta}+\alpha p_{j t}^{c}+\sigma \ln \left(\bar{s}_{j \mid g}\right)+\tau_{t}+\xi_{j t},
$$

where $\bar{s}_{j \mid g}$ denotes the market share of magazine $j$ at time $t$ in magazine group $g$ and $\tau_{t}$ denotes demand shocks that are the same for all magazines. The market share of the outside good, $s_{0}$, is $s_{0}=1-\sum_{j} s_{j t} \cdot{ }^{9}$

Finding an appropriate product grouping clearly is important since a misspecification of magazine demand leads to a misspecification of marginal cost. A 'natural' magazine grouping exists since industry publications such as Jahreszeitenverlag (1999-2002) differentiate between several magazine groups. I follow the industry grouping and distinguish between five women's magazine groups: (i) monthly high-priced, (ii) monthly medium-priced, (iii) biweekly classical, (iv) weekly advice-giving and (v) weekly entertaining. Table 3 displays the magazine grouping as well as other key figures related to the magazines analyzed in this paper.

\section{Insert Table 3 about here!}

Specifying marginal cost by $m c_{j t}=\boldsymbol{z}_{\boldsymbol{j} t} \boldsymbol{\gamma}+\omega_{j t}$, where $\boldsymbol{z}_{\boldsymbol{j} t}$ denotes marginal cost components that are observed by the econometrician and $\omega_{j t}$ denotes an unobserved marginal cost component, leads to the following joint estimation problem:

$$
\begin{array}{clc}
\ln \left(s_{j t}\right)-\ln \left(s_{0 t}\right) & = & \boldsymbol{x}_{\boldsymbol{j} \boldsymbol{t}} \boldsymbol{\beta}+\alpha p_{j t}^{c}+\sigma \ln \left(\bar{s}_{j \mid g}\right)+\tau_{t}+\xi_{j t} \\
p_{j t}^{c} & = & -\sum_{g} \eta_{g} D_{g} \frac{p_{j t}^{a} A D P_{j t}}{M_{t} s[.]}-\frac{s[.]}{\partial s[.] / \partial p_{j t}^{c}}+\boldsymbol{z}_{\boldsymbol{j} \boldsymbol{t}} \boldsymbol{\gamma}+\omega_{j t} \\
\ln \left(p_{j t}^{a}\right) & = & \boldsymbol{w}_{\boldsymbol{j} \boldsymbol{t}} \boldsymbol{\kappa}+\sum_{g} D_{g} \eta_{g} \ln \left(M_{t} s[.]\right)+\psi_{j t} .
\end{array}
$$

My specification of $\boldsymbol{x}_{\boldsymbol{j} \boldsymbol{t}}$ includes advertising share (the number of advertising pages over the total number of pages) and the number of editorial pages, both linearly and squared, so that there are four endogenous variables in this system: magazine price, $p_{j t}^{c}$, within group market shares, $\bar{s}_{j t \mid g}$, advertising share and the number of editorial pages.

Straightforward instruments for the endogenous variables are cost and quality

\footnotetext{
${ }^{9}$ Note that the framework chosen here allows consumers to purchase more than one magazine as long as the magazine purchase decision is uncorrelated with the number of magazines bought.
} 
characteristics (both from the magazine purchaser's and the advertiser's perspective) that appear in the equations other than in the equation in question. A drawback of my data, however, is that some of the explanatory variables are available on an annual basis only or do not vary over time at all while the endogenous variables vary quarterly. This causes the time-variation of some of the explanatory variables to be low (a low 'within' variation) so that orthogonality of these straightforward instruments cannot be accepted. I therefore use lags 1-4 of the endogenous variables as instruments. Orthogonality cannot be rejected at the usual significance levels ( $p$-value 0.8791).

Table 4 condenses the information contained in Table 3 by displaying the number of titles, the number of websites, circulation, advertising share (advertising pages relative to the total number of pages), magazine sales share and advertising sales share for each of the five magazine groups. 'Weekly entertaining' is the most densely populated category. It also owns the largest share in circulation but has both the lowest magazine and the lowest advertising sales share of all magazine groups. By contrast, 'monthly high-priced' magazines account only for a tiny fraction of circulation but occupy a relatively large share in magazine and advertising sales. There hence are apparent differences in the own-price elasticity of demand and in the circulation elasticity of advertising between the five magazine groups. This implies that treating different magazine groups differently in both market dimensions indeed is a sensible approach.

Insert Table 4 about here!

\section{Data and empirical specification}

\subsection{Data}

Data on circulation, cover prices, price per advertising page, number of advertising pages and the number of editorial pages is downloaded from the internet at http://medialine.focus.de. This data is available on a quarterly basis and spans the period I/1998 to IV/2001. The original source of this information is 'Information Association for the Determination of the Spread of Advertising Media' ('Informationsgemeinschaft zur Feststellung der Verbreitung von Werbeträgern e.V', IVW). IVW ascertains, monitors and publishes circulation and magazine dissemination information. All other information was originally gathered from the 'Association Media Analysis' ('Arbeitsgemeinschaft Media-Analyse', AG.MA), an association of the German advertising industry for the research of mass communication. The purpose of the AG.MA is to gather and to supply data for media audience measurement. AG.MA closely cooperates with IVW.

Magazine content information was obtained from Jahreszeitenverlag (1999-2002). Jahreszeitenverlag is a major German magazine publisher which made its annual 
publication 'Function-analysis: fact book of magazine contents and portraits' ('Funktions-Analyse: Factbook für Inhalte und Portraits von Zeitschriften') related to 1998, 1999, 2000 and 2001 available to me upon request. It contains content information taken from the respective year's first issue. Jahreszeitenverlag differentiates between 21 topics and provides data on the share of each of these topics in the total number of pages per issue. I condense this very detailed information to eleven topics: editorial service pages, TV program pages, counselling, fiction, fashion, hobby (comprising of cooking, handicraft, car, computer, vacation and interior design), beauty (cosmetics and health), information (politics, sciences and the arts), 'yellow' (sensational journalism and VIPs), partnership (partnership and sexuality) and children. The Jahreszeitenverlag publications also provides information on printing technique (offset print, photogravure print or a mixture of both) and physical size (length $\times$ width).

The exact date of website launching was assembled from email and telephone inquiries. Unfortunately, website traffic information is available for four magazines only, namely for 'Allegra', 'Brigitte', 'Elle' and 'freundin', so that I do not use this information here. ${ }^{10}$

The number of magazines that are published by the magazines' publishing houses are also assembled by email and telephone inquiries. They are available on an annual basis.

AG.MA provided me with data on consumer characteristics for 2000 (AG.MA 2001). This data is based on a consumer survey collected by the 'Institut für Demoskopie, Allensbach', Germany, in spring 2000. 20,606 interviews were realized. $^{11}$

Descriptive statistics of the variables involved in the estimation are presented in the Appendix.

\subsection{Empirical specification}

The vector of observed quality characteristics of the magazines, $\boldsymbol{x}_{\boldsymbol{j} \boldsymbol{t}}$, consists of the following variables: the natural logarithm of the number of editorial pages and its square, $\ln (E D P A G E S)$ and $\ln (E D P A G E S)^{2}$, the share of advertising pages and its square, $A D S H A R E$ and $A D S H A R E^{2}$, a dummy-variable for website provision, three dummy variables for the first to third quarter (with the fourth quarter being the comparison quarter), two dummy variables for 1999 and 2000 (with 2001 being the comparison year; I loose observations related to 1998 since I used lagged variables as instruments), the content share variables described above

\footnotetext{
${ }^{10}$ This data can be downloaded from http://www.ivw-online.de. It is monthly data that spans the period January 1998 to December 2001. A drawback of it is that it only contains information on the number of page impressions and the total number of website visitors but does not contain data on unique website visitors.

${ }^{11}$ For more information on this data, see http://www.awa-online.de/.
} 
(with 'children' being the comparison share) and the Hirshman-Herfindahl index of topic concentration.

The following variables that appear in the magazine demand specification are also treated as advertising demand shift variables, e.g. as elements of $\boldsymbol{w}_{j t}$ : the website provision dummy variable, the quarter dummy variables, the year dummy variables, the content share variables and the topic concentration variable. In addition, $\boldsymbol{w}_{\boldsymbol{j} t}$ consists of the shares of magazine purchasers with a monthly net income of 2,000-2,499 DM, 2,500-2,999 DM, 3,000-3,999 DM, 4,000-5,000 DM and more than 5,000 DM (with the share of magazine purchasers with an income below 2,000 DM being the comparison group), the share of magazine purchasers that is online, consumer age group concentration and income concentration (both measured in terms of a Hirshman-Herfindahl index).

Marginal cost components, $\boldsymbol{z}_{\boldsymbol{j} \boldsymbol{t}}$, include a dummy variable for offset print, a dummy variable for photogravure print (with the 'mixed' printing technique being the comparison group), the total number of pages, magazine size, the natural logarithm of the number of titles published by the own publishing house, the share of fashion pages in the total number of pages and the share of advertising pages. The latter two variables are included since fashion and advertising pages are printed in color which drives up production cost per page.

\section{$5 \quad$ Results}

GMM estimation results for the system of equations (8) are presented in Table 5. The standard errors are robust to autocorrelation and heteroscedasticity. Results of Wald-tests for joint significance are presented in Table 6. I shall discuss the results for each of the three equations separately. One result is, however, common to both the demand for magazines and the demand for advertising equation: website provision does not have a significant effect on either. This suggests that magazine websites and the magazines' print versions are neither complements nor substitutes. They rather are independent products.

\begin{tabular}{|c|}
\hline Insert Table 5 about here! \\
\hline Insert Table 6 about here! \\
\hline
\end{tabular}

\section{Magazine demand}

The price-coefficient $\alpha$ and within-group correlation $\sigma$ are both estimated with high precision. The estimated within-group correlation coefficient is 0.9036, which indicates that magazines within groups are close substitutes. Substitution is not perfect since $\sigma$ is highly significantly smaller than 1 .

Consumers appreciate a higher number of editorial pages per issue up to a limit 
that is reached at 155 editorial pages. To compare, the mean number of editorial pages is 99, the median is 70. Advertising share also has a concave effect on magazine demand. The maximum is reached at an advertising share of 40.6 per cent respectively. Mean and median advertising shares are 27.1 and 23.2 per cent. Magazine contents have a highly significant effect on magazine demand. With four exceptions — 'fiction', 'fashion', 'hobby' and 'yellow' — the effects of the topic shares are statistically indistinguishable from the comparison group 'children'. Sensational journalism and VIPs, summarized under the heading 'yellow', and 'fiction' have the largest positive effect on magazine demand. 'Fashion' and 'hobby' also have a statistically larger and positive effect on the demand for magazines than 'children'.

There are clear seasonal patterns present in the women's magazine market. Magazine demand is significantly higher in the first and the third quarter than in the second and fourth quarter. By contrast, magazine demand has remained fairly stable between 1999 and 2001.

The coefficient related to the Hirshman-Herfindahl index of topic concentration is highly significant and negative. This indicates that magazine consumers appreciate topic variety.

\section{Inverse demand for advertising}

The order of magnitude of the circulation elasticities of advertising are perfectly in line with what industry experts would have predicted: it is lowest for the 'monthly high-priced' magazines and highest for the 'biweekly classical' ones. Circulation hence matters least for the high-priced fashion magazines that have a clear content and readership focus. It matters most for the 'biweekly classical' magazines that come with a considerable topic variety and an unequally distributed readership in terms of age and income. The inverse of $\eta$ gives the elasticity of the demand for advertising. Except for the 'biweekly classical' magazines, advertising demand is elastic, e.g. $1 / \eta_{g}$ is significantly larger than one.

The group-specific dummy variables, which are jointly highly significant, indicate that 'monthly high-priced' magazines on average (controlled for other variables affect advertising demand) charge a significantly higher price for advertising than any other magazine group.

The content share variables have a jointly highly significant effect on advertising demand. The topic 'children', which is the base category, apparently is least attractive from an advertisers' perspective: the coefficients corresponding to all other content shares are highly significantly positive. Bestsellers in this sense are the topics 'information' and 'counselling'. A high share of these topics might indicate seriousness of the magazine to advertisers.

In contrast to magazine purchasers who value topic variety, advertisers prefer magazines with a high topic concentration. This result is in accordance with common industry knowledge: advertisers prefer magazines that focus on contents that preferably match well with their products. For example, a fashion 
advertiser will choose a magazine that devotes much attention to fashion since the readers of the magazine are clearly highly inclined to buy fashion for themselves.

The income share variables have a jointly highly significant effect on advertising prices. Most attractive from an advertiser's point of view are magazines with a high share of purchasers with an income between 2,000 and 2,499 DM and with an income above 5,000 DM. The nonlinear effect of income groups on inverse advertising demand is also reflected in the highly significantly negative effect of income concentration on advertising prices.

The share of magazine purchasers that is online and age concentration of the readership both do not have a significant effect on advertising prices.

\section{Marginal cost estimation}

Printing technique has a highly significant effect on marginal costs. Both offset printing and photogravure printing allow significantly cheaper production than a mixture of offset/photogravure printing, a result that coincides with publishing industry knowledge.

As expected, magazines with larger size (width $\times$ length) are more expensive to produce. The number of pages also has a highly significant and positive effect on marginal cost. The coefficient estimate indicates that, controlled for the other marginal cost influencing variables, one magazine page costs DM 0.026 to produce.

Circulation has a highly significant and negative effect on marginal cost, indicating returns to scale in production.

The number of magazine titles published by the own publishing house has a significantly negative effect on marginal cost. This points at returns to scope in the publishing industry.

Seasonal effects on marginal cost cannot be found as indicated by the jointly insignificant quarter dummies. There is, however, a significantly negative time trend that implies that marginal costs have been lowest in 1999 and steadily increased since then. This negative time trend might be attributable to constantly increasing paper prices.

Fashion share and advertising share have the expected positive effect on marginal cost, presumably due to higher printing costs of the colored pages. The coefficient of advertising share is, however, imprecisely measured and insignificantly different from zero.

The goodness of fit of the three estimated equations is very good. The adjusted $R^{2}$ ranges between 0.86 for the magazine demand equation and 0.88 for the inverse demand for advertising equation.

\section{External validation of the estimation results}

A somewhat natural test of the validity of my model is to check if my marginal cost estimates are basically in line with marginal cost estimates gathered from 
industry sources. Cost data are, however, extremely difficult to obtain and if they are obtained, they are often to be treated as a business secret. Indeed, these are the reasons why economists wish to estimate marginal cost in the first place. After a thorough internet search and several inquiries at publishing houses and at firms from the printing industry, I obtained data on marginal cost for four German magazines.

Marginal cost for two of these four magazine were obtained from the internet. They correspond to 'Der Schnitt' and 'Filter', both are cineastic magazines that are, compared to the women's magazines analyzed here, lower in circulation but almost equal as far as the number of pages is concerned. According to Gangloff (2001), who cites the editor-in-chief of 'Der Schnitt', the printing cost per copy (e.g. marginal cost) of this magazine is 1.80 DM. A business plan of 'Filter', a magazine that is financed by a venture capitalist, shows that the editors estimate that printing costs per copy are 1.50 DM (Filter 2001). The upper part of Table 7 compares these marginal cost estimates gathered from industry sources with the estimated marginal cost to those magazines that come closest to 'Der Schnitt' and 'Filter' in terms of the number of pages and in terms of circulation. One markedly distinguishing feature between the two cineastic magazines and the women's magazine is that the former are printed in black and white while they latter are printed in color. With regard to the fact that black and white magazines are less costly to print than colored ones and by keeping in mind that the industry sources estimated for printing costs might be downward biased (especially those for 'Filter' which are taken from a business plan), the upper part of Table 7 shows that my marginal cost estimates compare very well to those of the industry sources.

\section{Insert Table 7 about here!}

The lower part of Table 7 also contains additional marginal cost information. Due to business secrecy, the true identity of these magazines cannot be revealed so that I shall refer to 'Magazine X' and 'Magazine $\mathrm{Y}$ ' instead. ${ }^{12} \mathrm{I}$ also give intervals for circulation, the number of pages per issue and cover prices instead of presenting the exact data which refers to December 2001. The closest match in terms of similarity in circulation and the number of pages is that between 'Magazine $\mathrm{X}$ ' and 'Brigitte', and a comparison of the corresponding marginal cost estimates indicates that the industry source and my estimation results coincide to a large extent. 'Cosmopolitan' compares best to 'Magazine Y'. In that case, however, my marginal cost estimates exceed those from industry sources by far, a pattern that also holds for a comparison of 'Magazine $\mathrm{X}$ ' and 'Magazine $\mathrm{Y}$ ' with 'Amica', 'Elle' and especially 'Vogue'. ${ }^{13}$ By contrast, comparing the marginal cost of

\footnotetext{
${ }^{12}$ I owe this information to Ulrike Hasslöcher and Jörg Hüner.

${ }^{13}$ In the case of 'Vogue', it should be noted that the high marginal cost are mainly driven by the high share of fashion and advertising which, due to the high amount of photos, drive up
} 
'Allegra' and 'Magazine Y', the second-best match of the women's magazines, again shows that my estimates come close to the estimates of industry sources. One way of gaining further precision in the marginal cost estimation is to use a more flexible model for magazine demand. Using random coefficient models (Berry et al. 1995) is, however, tedious in this three equation context where cross-equation restrictions apply. ${ }^{14}$

\section{Internal validation of the estimation results}

Table 8 provides an overview of the most important implied estimation results. From an estimation result evaluation point of view, the last column of that table (column 11), 'Advertising price elasticity with respect to cover price', is the most interesting one. The corresponding numbers are calculated as

$$
\frac{\partial p_{j t}^{a}}{\partial p_{j t}^{c}} \frac{p_{j t}^{c}}{p_{j t}^{a}}=\sum_{g} D_{g} \eta_{g} p_{j t}^{a} \frac{\partial s[.]}{\partial p_{j t}^{c}} \frac{1}{s[.]} \frac{p_{j t}^{c}}{p_{j t}^{a}} .
$$

If the model derived in Section 3 is correct, then one would expect that those magazines that make losses from selling the magazines are those with the highest advertising price sensitivity with respect to cover prices - and a comparison of column 11 and the difference between cover prices and marginal cost (column 4) strongly suggests that such a relationship actually exists.

\section{Insert Table 8 about here!}

Another piece of validation is provided by the fact that 'Amica' decreased its cover price by 2 DM in May 2002. This suggests that the editors of 'Amica' consider their magazine as cover price elastic — presumably both in the magazine demand and in the advertising demand dimension. This is reflected in Table 8 that displays the reaction of advertising prices to a change in cover prices and the semi own-price elasticity: ${ }^{15}$ advertising prices of 'Amica' are indeed the most cover-price sensitive ones and the semi own-price elasticity (column 10) is the second highest within the group 'monthly medium priced magazines'.

Other indicators for the validity of my estimation results are that (i) all magazines cover marginal production costs by advertising revenue and that, consequently, all magazines make positive profits (at least without consideration of fixed production costs, see column 9) and (ii) 'Prima Carina', the only dropout from the market, made the smallest before-fixed-cost-profits of all magazines in III/1999, the quarter when it was pulled out of the market.

\footnotetext{
the estimated marginal cost.

${ }^{14}$ The same reason presumably made Berry and Waldfogel (1999) apply the nested logit model as well.

${ }^{15}$ The semi own-price elasticity in the nested logit model of differentiated product demand is given by: $\frac{\alpha}{1-\sigma}\left(1-\sigma \bar{s}_{j \mid g}-(1-\sigma)\right)$.
} 
Table 8 also displays the estimated semi own-price elasticities in column 10. By and large, the more expensive magazines tend to be less price elastic while the reverse is true for the less expensive titles. One exception is 'BILD der Frau' which is comparatively price inelastic and situated at the lower end of the price ladder. 'BILD der Frau' is the market leader in terms of circulation and unique in many respects so that this result is rather surprising.

A final takeaway from Table 8 is that neglecting the effect of the interdependence between magazine pricing and advertising demand would have led to implausibly high marginal cost since marginal cost then just equalled price plus the 'usual' markup.

\section{Conclusion}

Magazines markets have two special features. First, magazines are faced by two demand curves: magazine demand and advertising demand. Second, by launching websites, magazines recently started to produce an at least potentially perfect substitute for their own product.

This paper derives a simple model of the profit maximizing magazine firm. In contrast to earlier studies that make the somewhat unreasonable assumption that print media firms have direct control over both the advertising market and the magazine market, it is assumed that magazines have a direct influence on magazine demand only. By setting magazine prices, magazines determine the demand for copies and thereby the demand for advertising. The first-order condition for profit maximization in such a Bertrand game shows that magazine prices are deteriorated by the feedback of magazine pricing to advertising demand. Magazines might even price below marginal cost if they are highly dependent on advertising revenue and/or if advertising demand is very circulation elastic.

The first-order condition of profit maximization is estimated jointly with a magazine demand equation that is derived from a 'nested logit' model for differentiated products and an equation for the inverse demand for advertising which is derived from a constant elasticity framework. Data on German women's magazines that are tracked between 1998 and 2001 are used in the GMM estimation.

The main result of this paper is that the marginal cost estimation method proposed in this paper proves to meet well with marginal cost estimates gathered from industry sources. They are also 'internally consistent' in the sense that magazines whose demand for advertising is very sensitive to changes in cover prices charge cover prices that are markedly below marginal cost.

The second main result of this paper relates to the effect of website provision on magazine demand and advertising demand. It turns out that website provision neither has a significant effect on website provision nor on magazine demand. A descriptive analysis of the magazine websites shows that there are very limited 
possibilities of substitution between the online version and the print version of the magazines. Magazines rather seem to use their websites to provide information complementary to that contained in the current print edition, provide information on the magazine to advertisers, advertise the current print edition and presumably just do not want to be the last to go online.

Further research will focus on the question 'When do magazines go online?' since most magazines will provide a website in the medium run. 
Table 1: Women's magazines online history

\begin{tabular}{lrlc}
\hline \hline & $\begin{array}{c}\text { Online } \\
\text { since }\end{array}$ & \multicolumn{1}{c}{$\begin{array}{c}\text { Magazine } \\
\text { group }\end{array}$} & URL \\
\hline Allegra & I 1996 & Monthly medium-priced & www.allegra.de \\
Amica & I 1997 & Monthly medium-priced & www.amica.de \\
Bild der Frau & II 2001 & Weekly advice-giving & www.bildderfrau.de \\
Brigitte & IV 1997 & Biweekly classical & www.brigitte.de \\
Cosmopolitan & I 1998 & Monthly medium-priced & www.cosmopolitan.de \\
Elle & I 1996 & Monthly high-priced & www.elle.de \\
freundin & I 1996 & Biweekly classical & www.freundin.de \\
Für Sie & I 2001 & Biweekly classical & www.fuersie.de \\
Journal für die Frau & I 2001 & Biweekly classical & www.journal.de \\
Madame & III 2001 & Monthly high-priced & www.madame.de \\
Petra & III 2001 & Monthly medium-priced & www.petra.de \\
Vogue & III 2000 & Monthly high-priced & www.vogue.de \\
\hline \hline
\end{tabular}

Note: Madame contains advertising clients information only. Source: e-mail and telephone inquiries.

Table 2: Differences in internet access and internet use between purchasers of magazines with and without websites

\begin{tabular}{lrrrrrr}
\hline \hline & \multicolumn{2}{c}{ W/ website } & \multicolumn{2}{c}{ W/o website } & \multicolumn{2}{c}{$\begin{array}{c}\text { Ranksum } \\
\text {-test }\end{array}$} \\
& Mean & Median & Mean & Median & $p$-value & $p$-value \\
\hline General internet use & 26.7 & 26.8 & 11.2 & 10.3 & 0.0002 & 0.0001 \\
Internet used in private & 22.0 & 23.2 & 9.4 & 8.8 & 0.0001 & 0.0001 \\
Internet used in office & 11.5 & 10.9 & 4.7 & 4.4 & 0.0000 & 0.0001 \\
Internet access from home & 17.8 & 18.5 & 7.1 & 6.3 & 0.0002 & 0.0001 \\
Internet access from office & 8.3 & 7.4 & 3.1 & 2.7 & 0.0001 & 0.0001 \\
\hline \hline
\end{tabular}

Note: The table compares the shares of internet users between online and offline magazines. Source: AG.MA (2001). 
Table 3: Key figures

\begin{tabular}{|c|c|c|c|c|c|c|}
\hline & \multicolumn{3}{|c|}{ Magazine market } & \multicolumn{3}{|c|}{ Advertising market } \\
\hline & $\begin{array}{c}\text { Cover } \\
\text { price } \\
\text { (in DM) }\end{array}$ & $\begin{array}{c}\text { Market } \\
\text { share } \\
(\text { in } \%)\end{array}$ & $\begin{array}{l}\text { Within } \\
\text { group } \\
\text { market } \\
\text { share } \\
(\text { in \%) }\end{array}$ & $\begin{array}{c}\text { Price } \\
\text { per } \\
\text { page } \\
\text { (in } 1,000 \mathrm{DM})\end{array}$ & $\begin{array}{l}\text { Market } \\
\text { share } \\
(\text { in } \%)\end{array}$ & $\begin{array}{l}\text { Within } \\
\text { group } \\
\text { market } \\
\text { share } \\
(\text { in } \%) \\
\end{array}$ \\
\hline \multicolumn{7}{|c|}{ Monthly high-priced women's magazines } \\
\hline Elle & 7.9 & 1.4 & 37.8 & 20.1965 & 9.8 & 33.1 \\
\hline Madame & 11 & 0.7 & 17.1 & 14.6005 & 5.6 & 18.9 \\
\hline Marie Claire & 7 & 0.9 & 22.4 & 15.5128 & 4.3 & 14.5 \\
\hline Vogue & 11 & 0.9 & 22.7 & 20.6350 & 10 & 33.6 \\
\hline \multicolumn{7}{|c|}{ Monthly medium-priced women's magazines } \\
\hline Allegra & 5 & 1.3 & 10.5 & 14.2975 & 5.8 & 16.2 \\
\hline Amica & 6 & 1.8 & 14.9 & 17.5074 & 9.3 & 25.9 \\
\hline Cosmopolitan & 5 & 2.2 & 18.2 & 23.2108 & 8.3 & 23.3 \\
\hline Frau im Leben & 3.9 & 1.1 & 9.0 & 4.8570 & 0.87 & 2.4 \\
\hline Maxi & 5 & 1.8 & 14.9 & 11.9232 & 3.3 & 9.1 \\
\hline Petra & 5 & 1.7 & 14.2 & 21.5203 & 6.8 & 19.0 \\
\hline Ratgeber Frau und Familie & 4 & 2.2 & 18.3 & 5.5687 & 1.5 & 4.1 \\
\hline \multicolumn{7}{|c|}{ Biweekly classical women's magazines } \\
\hline Brigitte & 4 & 5.8 & 38.2 & 44.2702 & 5.9 & 29.5 \\
\hline freundin & 4 & 3.8 & 25.0 & 31.1512 & 6.9 & 34.4 \\
\hline Für Sie & 4 & 3.4 & 22.1 & 24.1657 & 4.5 & 22.2 \\
\hline Journal für die Frau & 4 & 2.3 & 14.7 & 14.8644 & 2.8 & 13.9 \\
\hline \multicolumn{7}{|c|}{ Weekly advice-giving women's magazines } \\
\hline bella & 2.4 & 2.1 & 7.5 & 13.1393 & 0.85 & 15.5 \\
\hline BILD der Frau & 1.6 & 11.1 & 39.5 & 37.6732 & 1.4 & 25.9 \\
\hline Laura & 1.6 & 3.5 & 12.3 & 12.5158 & 0.92 & 16.8 \\
\hline Lea & 1.7 & 1.6 & 5.8 & 5.6750 & 0.32 & 5.9 \\
\hline Lisa & 1.6 & 3.7 & 13.1 & 14.3000 & 0.86 & 15.7 \\
\hline tina & 2.4 & 6.1 & 21.8 & 29.5855 & 1.1 & 20.2 \\
\hline \multicolumn{7}{|c|}{ Entertaining weekly women's magazines } \\
\hline 7 Tage & 2.7 & 0.7 & 1.7 & 2.2066 & 0.61 & 6.8 \\
\hline Das Goldene Blatt & 2.7 & 1.6 & 3.8 & 5.3962 & 0.54 & 6.1 \\
\hline Das Neue & 2.7 & 2.8 & 6.8 & 5.4251 & 0.17 & 1.9 \\
\hline DAS NEUE BLATT & 2.7 & 6.5 & 15.9 & 10.6980 & 0.77 & 8.6 \\
\hline Die Aktuelle & 2.7 & 3.3 & 8.2 & 8.4829 & 0.69 & 7.7 \\
\hline Die Neue Frau & 1.8 & 1.4 & 3.3 & 3.7702 & 0.33 & 3.7 \\
\hline Echo der Frau & 2.7 & 2.6 & 6.4 & 4.9628 & 1 & 11.4 \\
\hline Frau aktuell & 2.7 & 2.1 & 5.2 & 4.8284 & 0.98 & 10.9 \\
\hline Frau im Spiegel & 2.7 & 3.8 & 9.3 & 13.0280 & 0.8 & 8.9 \\
\hline Frau mit Herz & 2.7 & 1.0 & 2.4 & 3.8799 & 0.65 & 7.2 \\
\hline Heim und Welt & 2.7 & 0.7 & 1.8 & 2.0258 & 0.81 & 9.1 \\
\hline NEUE POST & 2.7 & 8.2 & 20.2 & 13.1032 & 0.76 & 8.5 \\
\hline Neue Welt & 2.7 & 2.6 & 6.4 & 6.2184 & 0.51 & 5.8 \\
\hline neue Woche & 1.7 & 3.6 & 8.8 & 7.1100 & 0.3 & 3.4 \\
\hline
\end{tabular}

Note: The advertising price per page is calculated as the weighted average (weitghted by the respective number of advertising pages) of the price for black and white ads, two-color ads and four-color ads. The data refer to $\mathrm{IV} / 2001$. 
Table 4: Market shares of magazine groups

\begin{tabular}{|c|c|c|c|c|c|c|}
\hline Magazine group & $\begin{array}{l}\# \text { of } \\
\text { titles }\end{array}$ & $\begin{array}{l}\# \text { of } \\
\text { web- } \\
\text { sites }\end{array}$ & $\begin{array}{c}\text { Circu- } \\
\text { lation } \\
\text { share } \\
(\text { in } \%)\end{array}$ & $\begin{array}{l}\text { Adver- } \\
\text { tising } \\
\text { share } \\
\text { (in \%) }\end{array}$ & $\begin{array}{c}\text { Magazine } \\
\text { sales } \\
\text { share } \\
(\text { in } \%)\end{array}$ & $\begin{array}{c}\text { Advertising } \\
\text { sales } \\
\text { share } \\
(\text { in } \%)\end{array}$ \\
\hline Monthly high-priced & 4 & 2 & 3.9 & 29.7 & 26.7 & 26.7 \\
\hline Monthly medium-priced & 7 & 4 & 13.7 & 36.7 & 31.5 & 31.5 \\
\hline Biweekly classical & 4 & 4 & 16.3 & 28.9 & 44.5 & 44.5 \\
\hline Weekly advice-giving & 7 & 1 & 28.7 & 5.4 & 6.5 & 6.5 \\
\hline Weekly entertaining & 14 & 0 & 39.8 & 9.5 & 3.1 & 3.1 \\
\hline
\end{tabular}

Note: Data from IV/2001. Source: http://medialine.focus.de/. 
Table 5: GMM estimation results

\begin{tabular}{|c|c|c|c|c|c|c|}
\hline & \multicolumn{2}{|c|}{ Magazine demand } & \multicolumn{2}{|c|}{$\begin{array}{l}\text { Inverse adver- } \\
\text { tising demand }\end{array}$} & \multicolumn{2}{|c|}{ Marginal cost } \\
\hline & Coeff. & Std. err. & Coeff. & Std. err. & Coeff. & Std. err. \\
\hline Constant & $-16.4794^{* * *}$ & 5.6831 & $-8.8542^{* * *}$ & 1.2554 & $5.8978^{* * *}$ & 1.8559 \\
\hline$\alpha$ & $-0.1518^{* * *}$ & 0.0168 & & & & \\
\hline$\sigma$ & $0.9036^{* * *}$ & 0.0200 & & & & \\
\hline $\ln (E D P A G E S)$ & $4.8756^{* *}$ & 2.4680 & & & & \\
\hline $\ln (E D P A G E S)^{2}$ & $-0.4832^{*}$ & 0.2671 & & & & \\
\hline$A D S H A R E$ & $2.3457^{* * *}$ & 0.7160 & & & 1.4693 & 2.2785 \\
\hline$A D S H A R E^{2}$ & $-2.8928^{* * *}$ & 0.9863 & & & & \\
\hline Website & -0.0309 & 0.0554 & 0.0110 & 0.0328 & & \\
\hline 1st quarter & $0.0603^{* * *}$ & 0.0198 & $-0.0588^{* * *}$ & 0.0138 & -0.1490 & 0.1198 \\
\hline 2nd quarter & 0.0137 & 0.0220 & $-0.0287^{* *}$ & 0.0138 & -0.0398 & 0.1343 \\
\hline 3rd quarter & $0.0908^{* * *}$ & 0.0152 & $-0.0515^{* * *}$ & 0.0110 & -0.0931 & 0.1372 \\
\hline 1999 & -0.2422 & 0.0228 & $-0.0575^{* * *}$ & 0.0184 & $-0.3195^{* *}$ & 0.1335 \\
\hline 2000 & 0.0116 & 0.0234 & -0.0174 & 0.0175 & -0.1379 & 0.1386 \\
\hline Editorial info pages & 0.0147 & 0.1792 & $0.9701^{* * *}$ & 0.1656 & & \\
\hline TV program & 0.1595 & 0.1443 & $0.7783^{* * *}$ & 0.1229 & & \\
\hline Counselling & -0.1137 & 0.1905 & $1.0135^{* * *}$ & 0.1492 & & \\
\hline Fiction & $0.5090^{* * *}$ & 0.1236 & $0.7114^{* * *}$ & 0.1086 & & \\
\hline Fashion & $0.2376^{*}$ & 0.1281 & $0.8625^{* * *}$ & 0.1079 & $0.9289^{* *}$ & 0.4483 \\
\hline Hobby & $0.2905^{* *}$ & 0.1353 & $0.7584^{* * *}$ & 0.1235 & & \\
\hline Beauty & 0.2105 & 0.1375 & $0.7300^{* * *}$ & 0.1141 & & \\
\hline Information & -0.0991 & 0.1345 & $1.0055^{* * *}$ & 0.1262 & & \\
\hline Yellow & $0.5961^{* * *}$ & 0.1280 & $0.7885^{* * *}$ & 0.1140 & & \\
\hline Partnership & 0.2117 & 0.1386 & $0.8326^{* * *}$ & 0.1121 & & \\
\hline Topic concentration & $-0.0739^{* * *}$ & 0.0070 & $0.0165^{* *}$ & 0.0069 & & \\
\hline Group dummy 'monthly high-priced' & & & $6.3983^{* * *}$ & 0.9837 & & \\
\hline Group dummy 'monthly medium-priced' & & & 0.4427 & 1.7149 & & \\
\hline Group dummy 'biweekly classical' & & & $-2.0223^{*}$ & 1.2339 & & \\
\hline Group dummy 'weekly advice-giving' & & & -0.2902 & 0.7824 & & \\
\hline$\eta$ 'monthly high-priced' & & & $0.2446^{* * *}$ & 0.0864 & & \\
\hline$\eta$ 'monthly medium-priced' & & & $0.7253^{* * *}$ & 0.1234 & & \\
\hline$\eta$ 'biweekly classical' & & & $0.9322^{* * *}$ & 0.0860 & & \\
\hline$\eta$ ‘weekly advice-giving' & & & $0.8054^{* * *}$ & 0.0481 & & \\
\hline$\eta$ ‘weekly entertaining' & & & $0.7259^{* * *}$ & 0.0281 & & \\
\hline Share income $2,000-2,500$ & & & $4.8385^{* * *}$ & 0.7916 & & \\
\hline Share income $2,500-3,000$ & & & 0.4412 & 0.6912 & & \\
\hline Share income $3,000-4,000$ & & & 0.4348 & 0.9335 & & \\
\hline Share income $4,000-5,000$ & & & -0.5416 & 0.5843 & & \\
\hline Share income $5,000 \mathrm{p}$ & & & $4.8214^{* * *}$ & 0.6698 & & \\
\hline Share online & & & 0.0109 & 0.0083 & & \\
\hline Age concentration & & & -0.9852 & 1.3869 & & \\
\hline Income concentration & & & $-6.4717^{* * *}$ & 1.9391 & & \\
\hline Offset & & & & & $-1.6210^{* *}$ & 0.8323 \\
\hline Photogravure & & & & & $-1.8491^{* * *}$ & 0.3788 \\
\hline Size & & & & & $0.0417^{* *}$ & 0.0204 \\
\hline Pages per issue & & & & & $0.0261^{* * *}$ & 0.0022 \\
\hline $\ln$ (\#oftitles) & & & & & $-0.8101^{* * *}$ & 0.1696 \\
\hline $\ln ($ copies sold $)$ & & & & & $-0.4210^{* * *}$ & 0.1327 \\
\hline adj. $R^{2}$ & .8552 & & 0.8807 & & .8570 & \\
\hline
\end{tabular}

Note: Sargan test $6.6718, p$-value .8791 . The number of observations is 392 . 
Table 6: Results of Wald tests for joint significance

\begin{tabular}{lrc}
\hline \hline & Test stat. & $p$-value \\
\hline Magazine demand & & \\
$\ln (E D P A G E S)$ and $\ln (E D P A G E S)^{2}$ & 32.6949 & 0.0000 \\
$A D S H A R E$ and $A D S H A R E^{2}$ & 11.6929 & 0.0029 \\
Quarter dummies & 64.2177 & 0.0000 \\
Year dummies & 0.3652 & 0.8331 \\
Content shares & 451.4124 & 0.0000 \\
Inverse advertising demand & & \\
Group dummies & 60.9585 & 0.0000 \\
Set of $\eta$ 's & 1598.3830 & 0.0000 \\
Income shares & 125.4618 & 0.0000 \\
Content shares & 1147.5778 & 0.0000 \\
Marginal cost & & \\
Quarter dummies & 3.1712 & 0.3660 \\
Year dummies & 5.7031 & 0.0578 \\
Printing technique & 32.2659 & 0.0000 \\
Fashion and advertising shares & 22.1657 & 0.0000 \\
\hline \hline
\end{tabular}

Table 7: 'Actual' and estimated marginal cost comparison

\begin{tabular}{lrrrrr}
\hline \hline & $\begin{array}{c}\text { \# of copies } \\
\text { per issue }\end{array}$ & $\begin{array}{c}\text { \# of pages } \\
\text { per issue }\end{array}$ & $\begin{array}{c}\text { Marginal } \\
\text { cost (in DM) }\end{array}$ & $\begin{array}{c}\text { Cost } \\
\text { per page (in DM) }\end{array}$ & $\begin{array}{c}\text { Cover } \\
\text { price (in DM) }\end{array}$ \\
\hline Der Schnitt & 12,000 & 60 & 1.80 & 0.030 & 5.0 \\
Filter & 20,000 & 80 & 1.50 & 0.019 & 5.5 \\
7 Tage & 101,568 & 73 & 2.28 & 0.031 & 2.7 \\
Frau mit Herz & 148,578 & 77 & 1.97 & 0.025 & 2.7 \\
Heim und Welt & 108,526 & 78 & 2.37 & 0.030 & 2.7 \\
& & & & & \\
Magazine X & {$[700,000 ; 800,000]$} & {$[300 ; 350]$} & 7.00 & {$[0.023 ; 0.020]$} & {$[4 ; 5]$} \\
Magazine Y & {$[300,000 ; 350,000]$} & {$[250 ; 300]$} & 7.90 & {$[0.032 ; 0.026]$} & {$[6 ; 7]$} \\
Allegra & 192,002 & 291 & 9.21 & 0.032 & 5.0 \\
Amica & 271,603 & 399 & 12.96 & 0.033 & 6.0 \\
Brigitte & 878,632 & 270 & 7.86 & 0.029 & 4.0 \\
Cosmopolitan & 332,708 & 309 & 11.07 & 0.036 & 5.0 \\
Elle & 217,860 & 364 & 13.30 & 0.037 & 7.9 \\
freundin & 575,978 & 303 & 9.15 & 0.030 & 4.0 \\
Vogue & 130,720 & 393 & 17.33 & 0.044 & 11.0 \\
\hline \hline
\end{tabular}


Table 8: Marginal cost estimates and profits

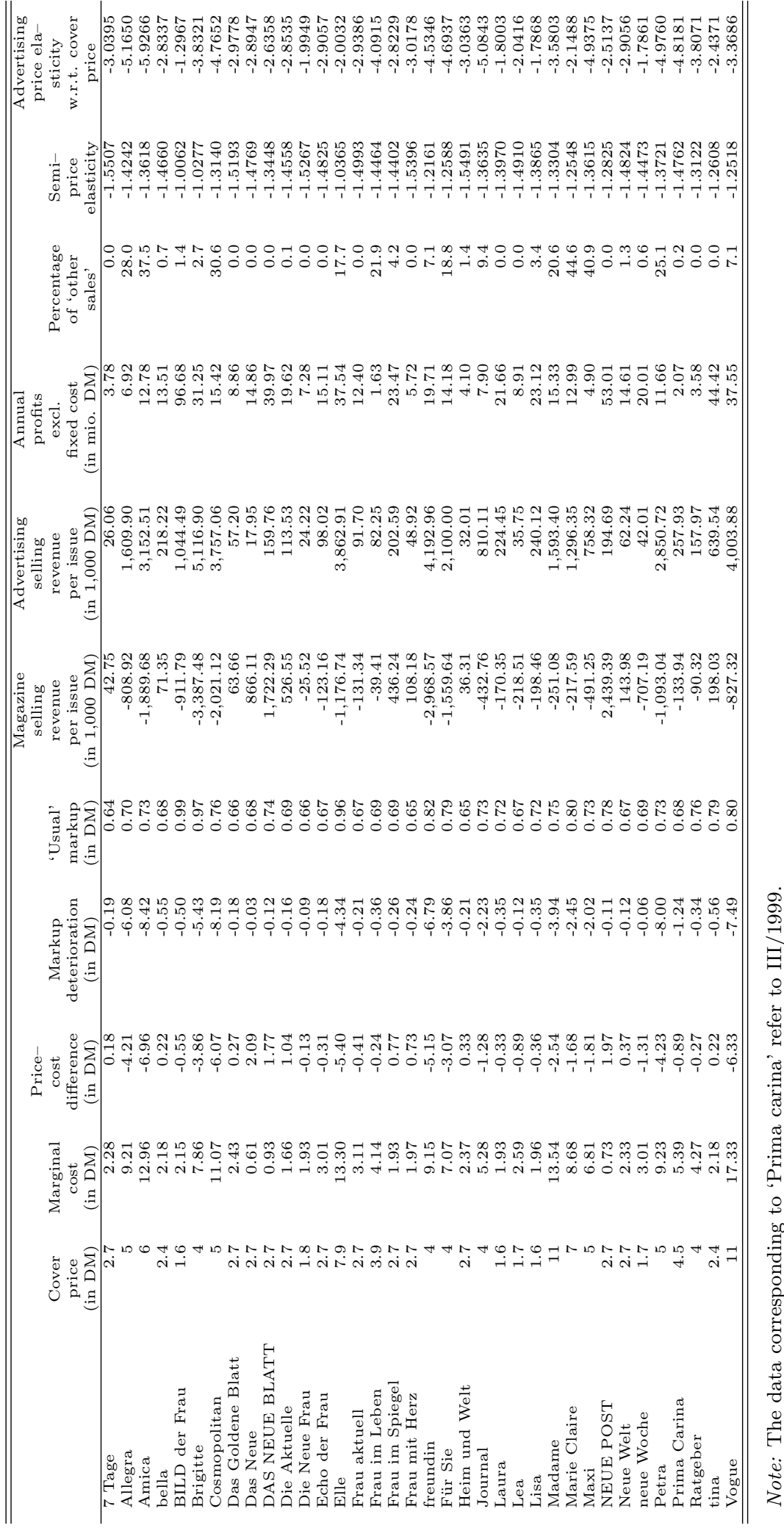


Appendix: Descriptive statistics

\begin{tabular}{|c|c|c|}
\hline & Mean & Std. dev. \\
\hline \multicolumn{3}{|l|}{ Explanatory and dependent variables } \\
\hline $\ln \left(s_{j} / s_{0}\right)$ & -4.5973 & 0.7404 \\
\hline$p^{c}($ in $\mathrm{DM})$ & 3.8347 & 2.3427 \\
\hline $\ln \left(s_{j \mid g}\right)$ & -2.1679 & 0.7979 \\
\hline $\ln (E D P A G E S)$ & 4.5000 & 0.4267 \\
\hline $\ln (E D P A G E S)^{2}$ & 20.4315 & 3.9506 \\
\hline$A D S H A R E$ & 0.2678 & 0.1328 \\
\hline$A D S H A R E^{2}$ & 0.8899 & 0.7848 \\
\hline Website & 0.2375 & \\
\hline 1st quarter & 0.2500 & \\
\hline 2nd quarter & 0.2500 & \\
\hline 3rd quarter & 0.2500 & \\
\hline 1999 & 0.3200 & \\
\hline 2000 & 0.3400 & \\
\hline Editorial pages & 0.5047 & 0.1328 \\
\hline TV program & 0.0980 & 0.2154 \\
\hline Counselling & 0.2262 & 0.1489 \\
\hline Fiction & 1.0697 & 0.7982 \\
\hline Fashion & 1.3744 & 1.2083 \\
\hline Hobby & 2.2443 & 1.1019 \\
\hline Beauty & 1.2517 & 0.4163 \\
\hline Information & 0.6166 & 0.4456 \\
\hline Yellow & 2.0658 & 1.3572 \\
\hline Love etc. & 0.4355 & 0.4639 \\
\hline Topic concentration & 14.8373 & 4.7322 \\
\hline $\ln \left(p^{a}\right)($ in $1,000 \mathrm{DM})$ & 9.2962 & 0.7688 \\
\hline Group dummy 'monthly high-priced' & 0.1200 & \\
\hline Group dummy 'monthly medium-priced' & 0.2100 & \\
\hline Group dummy 'biweekly classical' & 0.1200 & \\
\hline Group dummy 'weekly advice-giving' & 0.1500 & \\
\hline $\ln (M s) \cdot$ 'montly high-priced' & 1.4212 & 3.8545 \\
\hline $\ln (M s) \cdot$ 'montly medium-priced' & 2.6256 & 5.1011 \\
\hline $\ln (M s) \cdot$ 'classical' & 1.5985 & 4.3355 \\
\hline $\ln (M s) \cdot$ 'weekly advice-giving' & 2.0284 & 4.8391 \\
\hline $\ln (M s) \cdot$ 'weekly entertaining' & 5.1203 & 6.2956 \\
\hline Share income $2000-2500$ & 0.1042 & 0.0354 \\
\hline Share income $2500-3000$ & 0.1195 & 0.0322 \\
\hline Share income $3000-4000$ & 0.2128 & 0.0320 \\
\hline Share income $4000-5000$ & 0.1854 & 0.0352 \\
\hline Share income 5000p & 0.2422 & 0.1025 \\
\hline Share online & 8.5200 & 7.2083 \\
\hline Age concentration & 0.1881 & 0.0258 \\
\hline Income concentration & 0.2008 & 0.0355 \\
\hline Offset & 0.2200 & \\
\hline Photogravure & 0.6700 & \\
\hline Size & 61.6563 & 5.5417 \\
\hline Pages per issue & 150.3360 & 97.7475 \\
\hline $\ln (\#$ of titles $)$ & 2.4275 & 0.8366 \\
\hline $\ln ($ copies sold $)$ & 12.8089 & 0.7368 \\
\hline \multicolumn{3}{|l|}{ Instruments } \\
\hline $\ln \left(s_{j g \mid t-1}\right)$ & -2.1106 & 0.7348 \\
\hline$p_{j t-1}^{c}$ & 3.8344 & 2.3618 \\
\hline $\ln (E D P A G E S)_{j t-1}$ & 4.4988 & 0.3927 \\
\hline $\operatorname{ADSHARE}_{j t-1}$ & 0.2810 & 0.1217 \\
\hline
\end{tabular}




\section{References}

Anderson, S.P., A. de Palma and J.-F. Thisse, 1992, 'Discrete Choice Theory of Product differentiation' (The MIT Press, Cambridge, Massachusetts).

ACNielsen, 2002, 'Online-Bruttowerbeaufwendungen des Jahres 2001', press release; www.acnielsen.de/news/2002/01_22.htm.

AG.MA, 2001, MA 2000, 'Pressemedien II, Tageszeitungen', CD-Rom, (Arbeitsgemeinschaft Media-Analyse, Frankfurt/Main).

Berry, S.T., 1992, Estimating Discrete-choice Models of Oligopoly Product Differentiation, RAND Journal of Economics, 25, 242-262.

Berry, S.T. and A. Pakes, 1993, Some Applications and Limitations of Recent Advances in Empirical Industrial Organization: Merger Analysis, The American Economic Review Papers and Proceedings, 83, 247-252.

Berry, S.T., J. Levinsohn and A. Pakes, 1995, Automobile Prices in Market Equilibrium, Econometrica, 63, 841-890.

Berry, S.T. and J. Waldfogel, 1999, Free Entry and Social Inefficiency in Radio Broadcasting, RAND Journal of Economics, 30(3), 397-420.

Blair,R.D. and R.E. Romano, 1993, Pricing Decisions of the Newspaper Monopolist, Southern Economic Journal, 59(4), 721-732.

Bucklin, R.E., R.E. Caves and A.W. Lo, 1989, Games of Survival in the US Newspaper Industry, Applied Economics, 21, 631-649.

Chaudri, V., 1998, Pricing and Efficiency of a Circulation Industry: The Case of Newspapers, Information Economics and Policy, 10, 59-76.

Corden, W.M., 1952-193, The Maximisation of Profit by a Newspaper Firm, The Review of Economic Studies, 20(3), 181-190.

Dertouzos, J.N. and W.B. Trautmann, 1990, Economic Effects of Media Concentration: Estimates from a Model of the Newspaper Firm, The Journal of Industrial Economics, 39(1), 1-14.

Deutsche Fachpresse, 2001, 'Fachpresse Statistik 2000', (Deutsche Fachpresse, Frankfurt/Main); http://www.fachpresse.de/fred/abb/text2.pdf.

Ferguson, J.M., 1983, Daily Newspaper Advertising Rates, Local Media Crossownership, Newspaper Chains and Media Competition, Journal of Law 8 Economics, 26(3), 635-654. 
Filter, 2001, 'Businessplan 2001-2006';

http://www.filternetz.de/_dokumente/businessplan_FILTER.pdf

Gangloff, T.P., 2001, 'Filmzeitschriften jenseits von 'Cinema': Unter dem Radar'; http://www.igmedien.de/publikationen/m/2001/1_2/21.html.

Gentzkow, M., 2002, 'Print vs. Online Competition in Newspaper Markets', Harvard University mimeo.

Gruner + Jahr, 2002, 'Brigitte Käuferanalyse 2001' (Gruner + Jahr, Hamburg).

Jahreszeitenverlag, 1999, 'Funktions-Analyse: Factbook für Inhalte und Portaits von Zeitschriften FA 1998' (Jahreszeitenverlag, Hamburg).

Jahreszeitenverlag, 2000, 'Funktions-Analyse: Factbook für Inhalte und Portaits von Zeitschriften FA 1999' (Jahreszeitenverlag, Hamburg).

Jahreszeitenverlag, 2001, 'Funktions-Analyse: Factbook für Inhalte und Portaits von Zeitschriften FA 2000', (Jahreszeitenverlag, Hamburg).

Jahreszeitenverlag, 2002, 'Funktions-Analyse: Factbook für Inhalte und Portaits von Zeitschriften FA 2001', (Jahreszeitenverlag, Hamburg).

Kaiser, U., 2002, The Effects of Website Provision on the Demand for German Women's Magazines, NBER working paper 8806; http://papers.nber.org/papers/w8806.pdf.

Merrilees, W.J., 1983, Anatomy of a Price Leadership Challenge: An Evaluation of Pricing Strategies in the Australian Newspaper Industry, The Journal of Industrial Economics, 31(3), 291-311.

Reddaway, W.B., 1963, The Economics of Newspapers, The Economic Journal, $73(290), 201-218$.

Röller, L.H., D. J. Stenback and F. Verboven, 2000, Efficiency Gains from Mergers, Wissenschaftszentrum Berlin für Sozialforschung Discussion Paper FS IV 00-09.

Rosse, J.N., 1967, Daily Newspapers, Monopolistic Competition, and Economies of Scale, The American Economic Review, 57(2), 522-533.

Rosse, J.N., 1970, Estimating Cost Function Parameters Without Using Cost Data: Illustrated Methodology, Econometrica, 38(2), 256-275.

Rosse, J.N., 1978, The Evolution of One Newspaper Cities, Studies in Industrial Economics 56, Stanford University, Dept. of Economics. 
Rysman, M., 2000, Competition Between Networks: A Study of the Market for Yellow Pages, Boston University mimeo.

Thompson, R.S., 1989, Circulation Versus Advertiser Appeal in the Newspaper Industry: An Empirical Investigation, The Journal of Industrial Economics, 37(3), 259-271.

Wagner, K., 1981, The Newspaper Industry in Britain, Germany and the United States, National Institute Economic Review, 95, 81-88. 